\title{
Seizures and Syncope Due to Complete Atrioventricular Block in a Patient with Acute Myocarditis with a Normal Left Ventricular Systolic Function
}

\author{
Ryohei Akashi ${ }^{1}$, Yoshihisa Kizaki ${ }^{1}$, Hiroaki Kawano ${ }^{3}$, Yasushi Takahara ${ }^{1}$, Kojiro Nakao ${ }^{1}$, \\ Nobuhisa Yonemitsu $^{2}$, Saburo Kusumoto ${ }^{3}$ and Koji Maemura ${ }^{3}$
}

\begin{abstract}
A 43-year-old man was admitted to our hospital presenting with seizures and syncope. He had a history of a cold with a fever of $39^{\circ} \mathrm{C}$ occurring three days earlier. Electrocardiography (ECG) showed complete atrioventricular block (AV block) with a maximum pause of 32 seconds, for which temporary pacing was performed. Echocardiography showed mild hypertrophy of the left ventricle (LV) with a normal ejection fraction of $61 \%$. Coronary angiography showed normal coronary arteries. Then, an endomyocardial biopsy was performed, the results of which indicated a diagnosis of acute myocarditis. After admission, the complete atrioventricular block disappeared together with normalization of the LV wall thickness.
\end{abstract}

Key words: Adams-Stokes syndrome, acute myocarditis, right bundle branch block, syncope

(Intern Med 51: 3035-3040, 2012)

(DOI: 10.2169/internalmedicine.51.8410)

\section{Introduction}

Myocarditis, inflammation of the myocardium, is associated with a number of etiologies and complications. Although conduction disturbances, such as complete atrioventricular block (AV block), may occur as serious complications of myocarditis, AV block is generally considered to be a rare complication, especially in the absence of severe forms of myocarditis with cardiac decompensation. We herein report the case of an adult patient with seizures and syncope related to complete AV block due to acute myocarditis without cardiac decompensation.

\section{Case Report}

A 43-year-old man was transferred by ambulance to our hospital to treat convulsions and syncope. He had three seizures in the ambulance. The electrocardiography ECG monitor in the ambulance showed complete AV block and an escape rhythm with a heart rate (HR) of 45 beats per minute (bpm). The monitor did not work during the seizures because the seizures induced electrical artifact in the ECG. The patient had experienced a cold with flu-like symptoms and a fever of $39^{\circ} \mathrm{C}$ three days earlier. He had no past medical history, and chest X-ray and ECG performed at his medical check-up were both normal. His family history was unremarkable.

On admission, the patient's blood pressure was 110/70 $\mathrm{mmHg}$, his pulse rate was $40 \mathrm{bpm}$ and his temperature was $37.4^{\circ} \mathrm{C}$. A physical examination revealed no abnormal findings. Chest X-ray obtained with the patient in the supine position showed cardiomegaly with clear lung fields (Fig. 1A). ECG showed complete AV block, left axis deviation (LAD), right bundle branch block (RBBB) and negative $\mathrm{T}$ waves in leads $\mathrm{I}, \mathrm{a} \mathrm{V}_{\mathrm{L}}$ and $\mathrm{V}_{3-6}$ (Fig. 1B). Ultrasound cardiography showed mild hypertrophy of the left ventricle (LV) (an interventricular septum (IVS) of $11 \mathrm{~mm}$ and a posterior wall thickness of $11 \mathrm{~mm}$ ), a normal LV ejection fraction of $61 \%$ and slight pericardial effusion (Fig. 1C).

The laboratory data obtained on admission are shown in Table. The hemoglobin level and white blood cell counts

${ }^{1}$ Department of Cardiology, Sasebo Chuo Hospital, Japan, ${ }^{2}$ Department of Pathology, Sasebo Chuo Hospital, Japan and ${ }^{3}$ Department of Cardiovascular Medicine, Nagasaki University Graduate School of Biomedical Sciences, Japan

Received for publication June 19, 2012; Accepted for publication July 20, 2012

Correspondence to Dr. Hiroaki Kawano, hkawano@nagasaki-u.ac.jp 


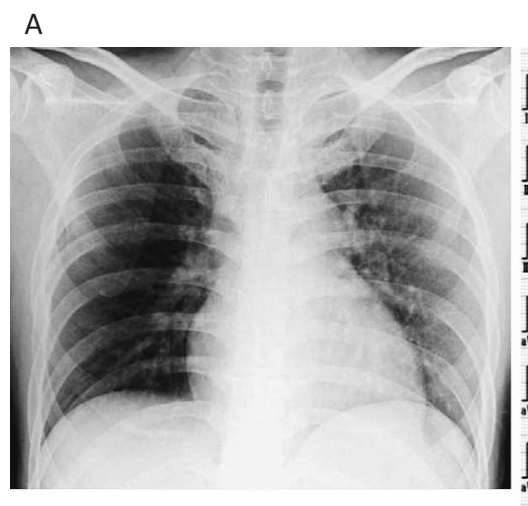

B
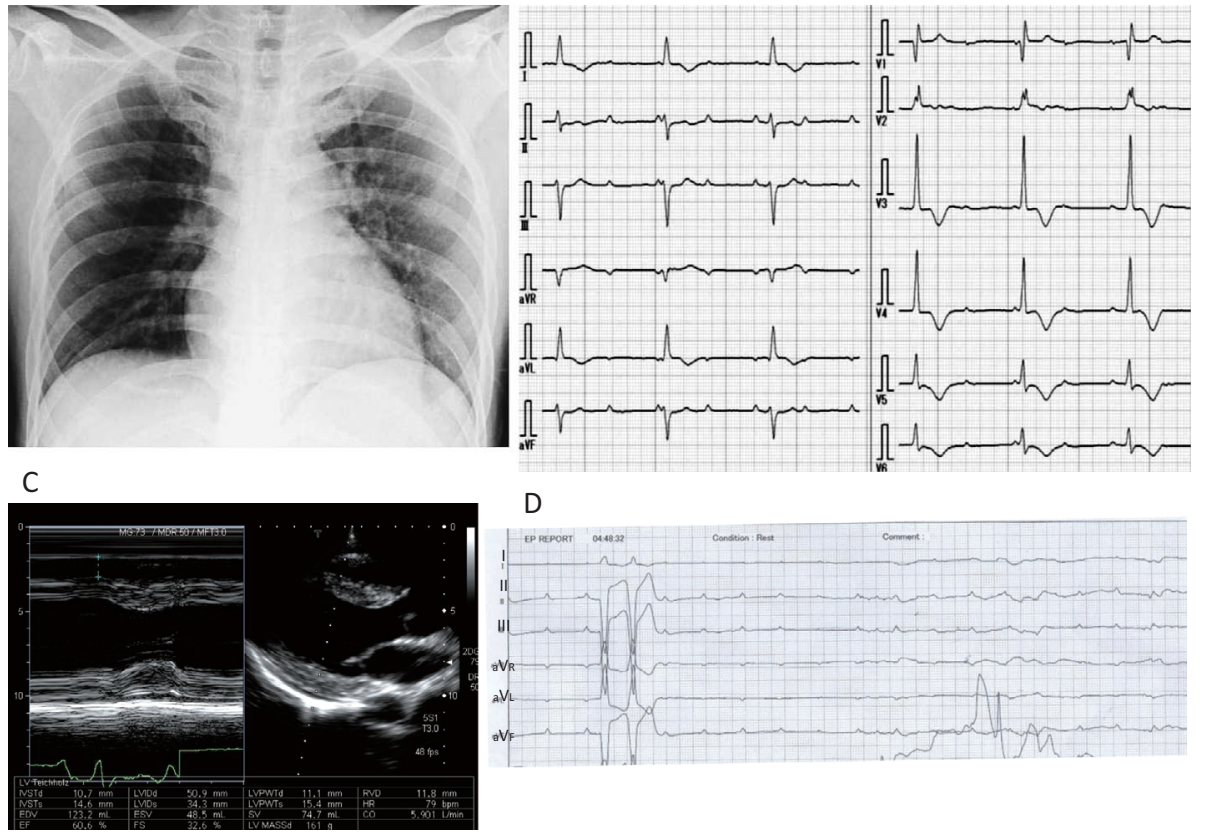

D

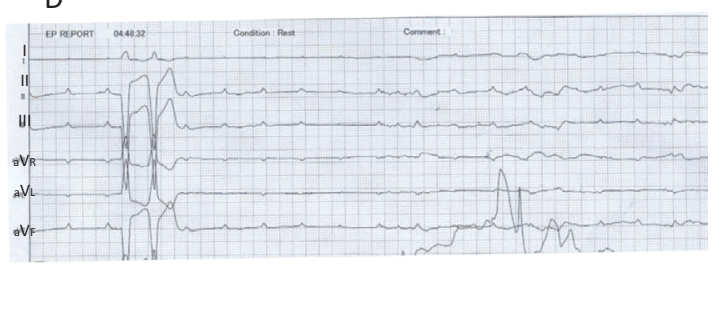

Figure 1. A) Chest X-ray showing cardiomegaly without lung congestion. B) On admission, ECG showed complete AV block, left axis deviation (LAD), right bundle branch block (RBBB) and negative $T$ waves in leads $I, a V_{L}$ and $V_{3-6 .} C$ ) Echocardiography showed mild left ventricular $(L V)$ hypertrophy, a normal $\mathrm{LV}$ ejection fraction of $61 \%$ and mild pericardial effusion. D) After admission, ECG showed a long pause of 32 seconds due to complete AV block with a sinus rate of 100 beats/ $\min$.

Table. Laboratory Data

\begin{tabular}{|c|c|c|c|c|c|}
\hline WBC & $8,400 / \mu \mathrm{L}$ & $\mathrm{TP}$ & $6.8 \mathrm{~g} / \mathrm{dL}$ & CK & $576 \mathrm{mg} / \mathrm{dL}$ \\
\hline Neutrophil & $67.5 \%$ & $\mathrm{Na}$ & $140 \mathrm{mEq} / \mathrm{L}$ & CRP & $5.2 \mathrm{mg} / \mathrm{dL}$ \\
\hline Eosinophil & $0.2 \%$ & $\mathrm{~K}$ & $3.6 \mathrm{mEq} / \mathrm{L}$ & Troponin $\mathrm{T}$ & $>2.0 \mathrm{ng} / \mathrm{mL}$ \\
\hline Lymphcyte & $20.5 \%$ & $\mathrm{Cl}$ & $103 \mathrm{mEq} / \mathrm{L}$ & H-FABP & $(+)$ \\
\hline Monocyte & $10.8 \%$ & BUN & $24.4 \mathrm{mg} / \mathrm{dL}$ & BNP & $151 \mathrm{pg} / \mathrm{mL}$ \\
\hline $\mathrm{RBC}$ & $464 \times 10^{4} / \mu \mathrm{L}$ & $\mathrm{Cr}$ & $1.0 \mathrm{mg} / \mathrm{dL}$ & $\mathrm{ACE}$ & $17.3 \mathrm{U} / \mathrm{L}$ \\
\hline $\mathrm{Hb}$ & $14.5 \mathrm{~g} / \mathrm{dL}$ & AST & $131 \mathrm{IU} / \mathrm{L}$ & & \\
\hline Het & $42.2 \%$ & ALT & 74 IU/L & & \\
\hline PLT & $19.4 \times 10^{4} / \mu \mathrm{L}$ & LDH & $415 \mathrm{IU} / \mathrm{L}$ & & \\
\hline
\end{tabular}

were normal. The serum level of C-reactive protein was 5.2 $\mathrm{mg} / \mathrm{dL}$, and the serum levels of creatine kinase (CK), aspartate aminotransferase and lactate dehydrogenase were elevated on admission. The serum was positive for troponin $\mathrm{T}$ and the serum level of brain natriuretic peptide was $151 \mathrm{pg} /$ $\mathrm{mL}$.

No prominently increased levels of circulating virus antibodies were found using paired titers, including coxsackie virus $\mathrm{A}$ and $\mathrm{B}$, echovirus, adenovirus and the influenza $\mathrm{A}$ and $\mathrm{B}$ viruses.

After admission, temporary pacing was immediately performed to treat complete AV block. During the procedure, the patient had a seizure with a maximum pause of $32 \mathrm{sec}-$ onds on ECG due to the complete AV block (Fig. 1D). The complete AV block disappeared on the third day after admission without any medication administration. At that time, ECG demonstrated that the LAD had disappeared. Additionally, negative $\mathrm{T}$ waves were seen in leads II, III and $\mathrm{aV}_{\mathrm{F}}$, and poor $\mathrm{R}$ wave progression was seen in the precordial leads (Fig. 2). On the seventh day after admission, the negative $\mathrm{T}$ waves had disappeared, although RBBB was observed (Fig. 2).

The CK serum levels were the highest at the time of admission and then gradually decreased thereafter (576 IU/L on admission, $139 \mathrm{IU} / \mathrm{L}$ on the $3 \mathrm{rd}$ day and $77 \mathrm{IU} / \mathrm{L}$ on the 7 th day). 

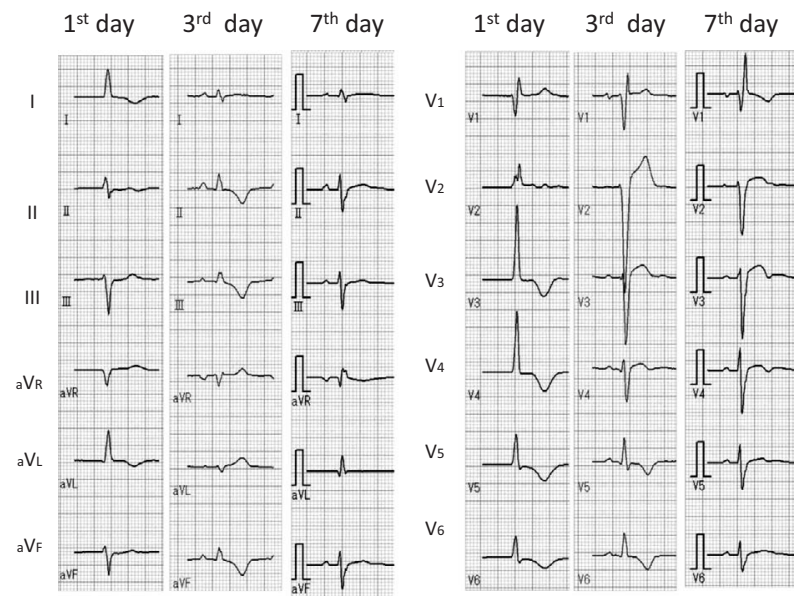

Figure 2. The time course of the patient's ECG. On the third day after admission, ECG showed the disappearance of the LAD, the presence of negative $T$ waves in leads II, III and $\mathbf{a V}_{\mathrm{F}}$ and poor $\mathrm{R}$ wave progression in the precordial leads. By the seventh day after admission, the negative $T$ waves had disappeared, although RBBB was still seen.

On the sixth day after admission, cardiac catheterization and an electrophysiological study were performed. Coronary angiography (CAG) showed no significant stenosis, and left ventriculography (LVG) demonstrated a normal ejection fraction of $62.1 \%$ (Fig. 3). An endomyocardial biopsy was also performed to evaluate the cause of the complete AV block. Histological studies of the biopsy specimen demonstrated lymphocytic infiltration, interstitial edema, interstitial fibrosis and myocyte necrosis, although there were no findings of specific types of myocarditis such as giant cells or eosinophil infiltration (Fig. 4). These findings suggested a diagnosis of acute lymphocytic myocarditis.

Permanent pacemaker implantation was not required because a treadmill test did not induce AV block and the electrophysiological study (EPS) suggested a preserved AV conduction function, as indicated by an (AA) of $792 \mathrm{~ms}$, an $(\mathrm{AH})$ of $100 \mathrm{~ms}$, an $(\mathrm{HV})$ of $49 \mathrm{~ms}$, a sinus node recovery time of $1,069 \mathrm{~ms}$ and a Wenckebach point of $100 \mathrm{bpm}$. Twenty days after admission, after observing normalization of the LV wall thickness and disappearance of the pericardial effusion on UCG, the patient was discharged from the hospital.

Follow-up performed approximately two months after admission showed a normal chest X-ray. Additionally, followup ECG showed persistence of the RBBB with amelioration of the $\mathrm{R}$ wave progression and follow-up UCG showed a normal LV systolic function without pericardial effusion (Fig. 5).

\section{Discussion}

Cardiac arrhythmias such as complete AV block can occur with nonspecific and specific myocarditis, including that due to sarcoidosis. Previous reports have shown that AdamsStokes attacks or syncope can occur due to the sudden onset of complete AV block in patients with acute nonspecific myocarditis, especially children and young adults (1-16). There are eight previous reports of seizures occurring due to complete AV block with acute myocarditis in children and adolescents $(1,7-10,14-16)$ and only one precise case in adults (13). This indicates that children and young adults are particularly vulnerable to these complications.

Our patient experienced seizures due to complete $\mathrm{AV}$ block with cardiac arrest of 32 seconds duration resulting from acute myocarditis that was successfully treated with a temporary pacemaker. Complete AV block in this patient was thought to be an isolated feature that could be rapidly and fully addressed if diagnosed early and treated with emergency pacemaker implantation (17). However, deaths from complete AV block leading to ventricular arrest have been reported $(18,19)$, and sudden cardiac death may be the initial presentation of myocarditis in some patients with complete AV block or ventricular tachycardia.

The outcomes of patients with complete AV block complicated by myocarditis are variable. Most patients recover normal heart function after suffering from myocarditis with complete AV block. The incidence of persistence of complete AV block reported in previous studies is $22 \%$ to $27 \%(1,2)$.

The myocardial damage that occurred in our patient was mild and no typical cardiac symptoms were observed, such as dyspnea due to heart failure, chest pain related to the myocarditis itself or associated pericarditis. Although the complete AV block observed in the present case was severe, it disappeared three days after its occurrence, with EPS showing normal AV conduction after the patient's recovery. Previous reports have demonstrated that the average time for recovery from complete $\mathrm{AV}$ block in children is 3.3 days (2). Arima et al. (13) reported an adult case of myocarditis involving seizures due to complete AV block. However, their patient had fulminant myocarditis, persistent complete AV block and a recurrence of myocarditis. Previous studies on the clinical and experimental histopathology of myocarditis suggest that myocardial interstitial edema and neural tissue damage are implicated in the transient conduction disturbances of acute myocarditis $(20,21)$. This suggests that transient complete AV block occurring in patients with acute myocarditis, as in our case, can develop even in the absence of severe myocarditis and has the potential to cause direct damage to the $\mathrm{AV}$ conduction system. In this case, the precise myocardial damage area could not be evaluated because the patient did not undergo other imaging studies such as myocardial scintigraphy or gadoliniumenhanced cardiac magnetic resonance imaging (cMRI). Therefore, the presence of injury or lesions around the AV node could not be determined.

In the present case, seizures and syncope were the primary symptoms. Mahoney et al. stated that Stokes-Adams seizures may be the only clinical manifestation of myocarditis with complete AV block in children (22). Therefore, in some cases, the diagnosis of acute myocarditis may be diffi- 


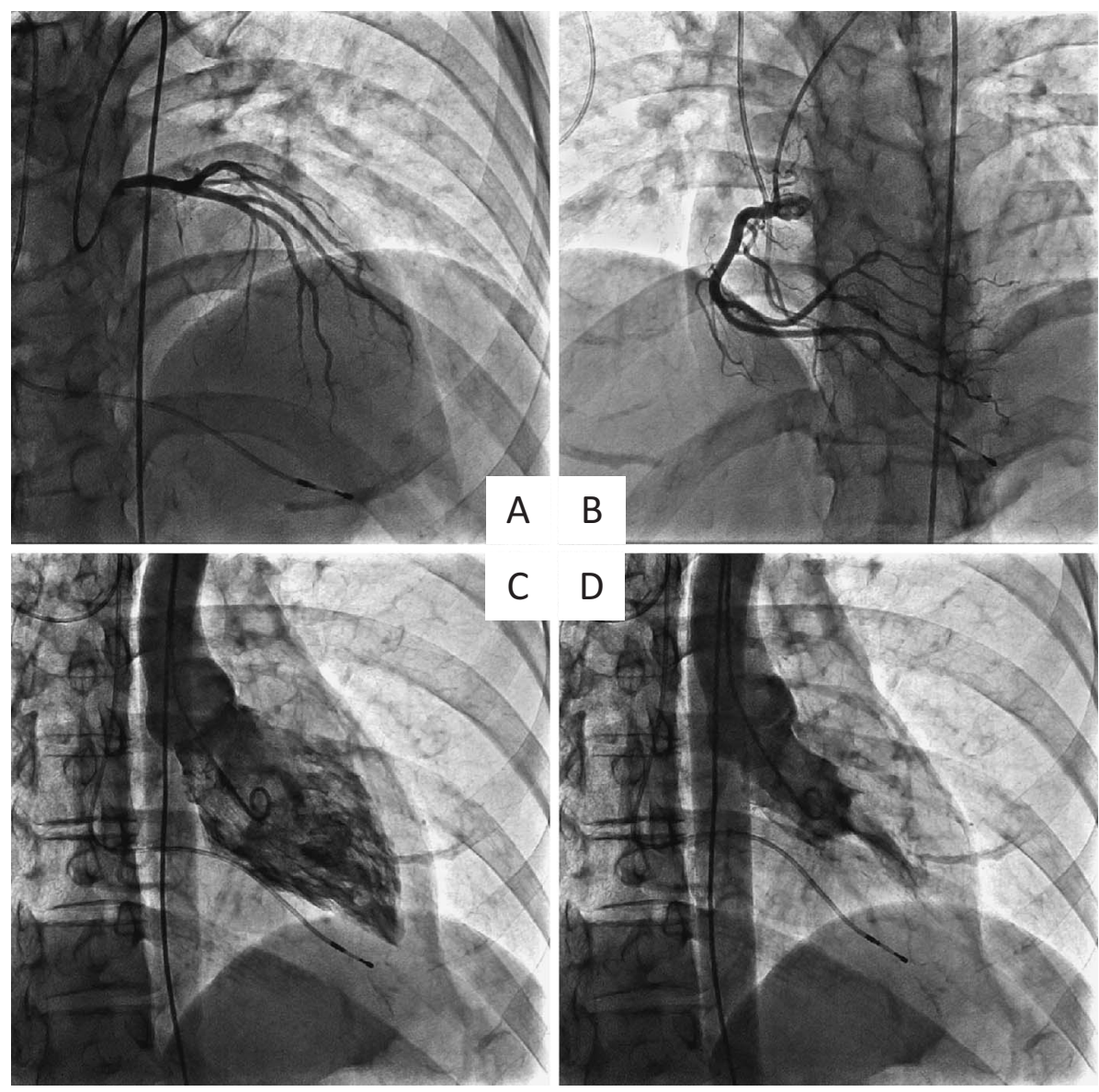

Figure 3. Coronary angiography (CAG) showed no significant stenosis, and left ventriculography (LVG) demonstrated a normal ejection fraction of $62.1 \%$ (A, CAG of the left coronary artery; B, CAG of the right coronary artery; C, the end-diastolic phase of LVG; D, the end-systolic phase of LVG).

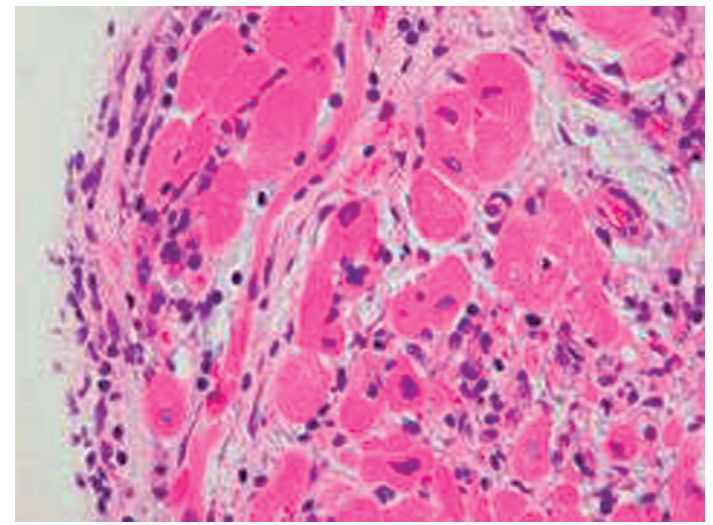

Figure 4. A microphotograph of the endomyocardial biopsy of the left ventricle demonstrating lymphocytic infiltration, interstitial edema, interstitial fibrosis and myocyte necrosis. However, there were no findings of specific myocarditis such as giant cells or eosinophil infiltration (Hematoxylin and Eosin staining, magnification $\times 100$ ).

cult to make using only ordinary non-invasive examinations. In our case, UCG showed a normal LV systolic function with mild LV hypertrophy due to myocardial edema associated with the myocarditis and slight pericardial effusion. An endomyocardial biopsy was performed to determine the diagnosis of acute myocarditis.

Gadolinium-enhanced cardiac magnetic resonance imaging (cMRI) is able to detect myocarditis-related injuries. Prochnau et al. (23) reported that gadolinium-enhanced cMRI is useful for diagnosing acute myocarditis with complete AV block. However, their patient had persistent complete AV block, and MRI cannot be performed in patients with temporary pacing or permanent pacemaker implantation. Hence, endomyocardial biopsies may be clinically indicated for diagnosing complete AV block in patients with acute myocarditis. Endomyocardial biopsies also provide information regarding the post-treatment status of patients. Based on the guidelines related to regarding the use of endomyocardial biopsies in patients with myocarditis, endomyocardial biopsies are an important diagnostic tool for making a diagnosis of acute myocarditis, including giant cell myocarditis and eosinonphilic myocarditis, in order to decide whether to administer corticosteroids and/or immunosuppressants $(24,25)$.

The cause of myocarditis was not determined in the present case. Previous reports in adults have demonstrated that Lyme disease, a tick-borne spirochetal infection, is a cause of transient complete AV block. Lyme disease is diagnosed 
A

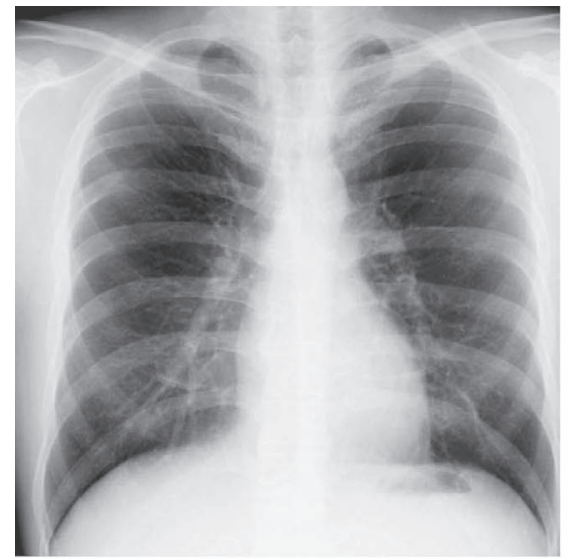

C

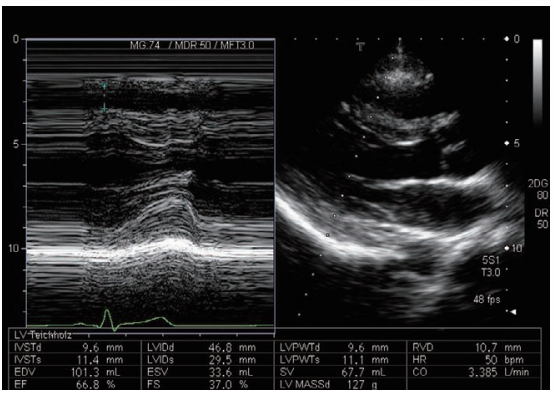

B

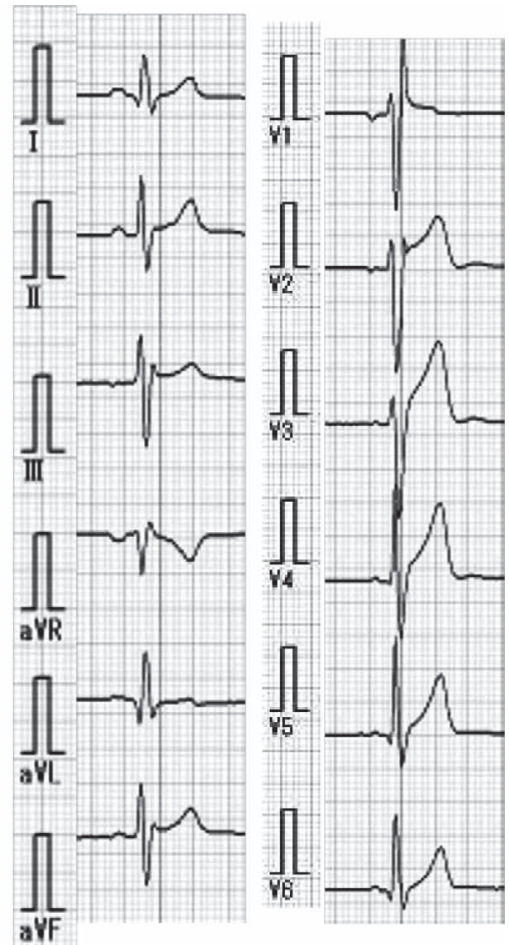

Figure 5. Follow-up of the patient approximately two months after admission showed a normal chest X-ray (A). Follow-up ECG showed persistence of the RBBB and amelioration of the $R$ wave progression (B), and follow-up UCG showed a normal LV systolic function without pericardial effu$\operatorname{sion}(\mathbf{C})$.

using serologic tests and treated with antibiotics (26). Therefore, we considered Lyme disease in the differential etiological diagnosis of our patient's symptoms. However, the patient's clinical course and the results of the endomyocardial biopsy were more suggestive of either a nonspecific or viral infection.

In conclusion, a diagnosis of acute myocarditis should be considered in patients presenting with seizures or syncope after the occurrence of flu-like symptoms, even in the absence of symptoms of heart failure, chest pain or signs of cardiac dysfunction.

The authors state that they have no Conflict of Interest (COI).

\section{References}

1. Chien SJ, Liang CD, Lin IC, Lin YJ, Huang CF. Myocarditis complicated by complete atrioventricular block: nine years' experience in a medical center. Pediatr Neonatol 49: 218-222, 2008.

2. Batra AS, Epstein D, Silka MJ. The clinical course of acquired complete heart block in children with acute myocarditis. Pediatr Cardiol 24: 495-497, 2003.

3. Das Gupta R, Das MK, Mitra S, Tagore R, Lahiri D. Acute nonspecific carditis in adolescents presenting with Stokes-Adams attacks. J Assoc Physicians India 47: 1195-1197, 1999.

4. Fujiwara T, Akiyama Y, Narita H, et al. Idiopathic acute myocarditis with complete atrioventricular block in a baby. Clinicopathological study of the atrioventricular conduction system. Jpn Heart J 22: 275-280, 1981.

5. Onouchi Z, Haba S, Kiyosawa N, Shimazu S, Hamaoka K, Kusunoki T. Stokes-Adams attacks due to acute nonspecific myo- carditis in childhood. Jpn Heart J 21: 307-315, 1980.

6. Johnson JL, Lee LP. Complete atrioventricular heart block secondary to acute myocarditis requiring intracardiac pacing. J Pediatr 78: 312-316, 1971.

7. Wang JN, Tsai YC, Lee WL, Lin CS, Wu JM. Complete atrioventricular block following myocarditis in children. Pediatr Cardiol 23: 518-521, 2002.

8. Wang JN, Wu JM, Lin CS, Liu CC, Yang YJ. Myocarditis with complete atrioventricular block associated with herpes simplex virus infection: report of one case. Zhonghua Min Guo Xiao Er Ke Yi Xue Hui Za Zhi 38: 381-384, 1997.

9. Wu JM, Wang JN, Lin CS, Lee WL. Trifascicular block with intermittent complete atrioventricular block in a child. J Formos Med Assoc 96: 921-924, 1997.

10. Mahoney LT, Marvin WJ Jr, Atkins DL, Clark EB, Lauer RM. Pacemaker management for acute onset of heart block in childhood. J Pediatr 107: 207-211, 1985.

11. Lim CH, Toh CC, Chia BL, Low LP. Stokes-Adams attacks due to acute nonspecific myocarditis. Am Heart J 90: 172-178, 1975.

12. Granath A, Kimby E, Södermark T, Volpe U, Zetterquist S. Stokes-Adams attacks requiring pacemaker treatment in three patients with acute nonspecific myocarditis. Acta Med Scand 207: 177-181, 1980.

13. Arima M, Kanoh T, Kawano Y, et al. Recurrence of myocarditis presenting as pacing and sensing failure after implantation of a permanent pacemaker at first onset. Jpn Circ J 65: 345-348, 2001.

14. Khongphatthanayothin $A$, Chotivitayatarakorn $P$, Benjacholamas V, Muangmingsuk S, Lertsupcharoen P, Thisyakorn C. Complete heart block in children at King Chulalongkorn Memorial Hospital. J Med Assoc Thai 84 (Suppl 1): S111-S117, 2001.

15. Yu TH, Guo GF, Chen MC, Yang CH. Reversible infra-Hisian atrioventricular block in acute myocarditis. Chang Gung Med J 24: 651-656, 2001.

16. Chavda KK, Dhuper S, Madhok A, Chowdhury D. Seizures sec- 
ondary to a high-grade atrioventricular block as a presentation of acute myocarditis. Pediatr Emerg Care 20: 387-390, 2004.

17. Heitink-Polle KM, Rammeloo L, Hruda J, Plotz FB. Rapid and full recovery after life-threatening complete atrioventricular block: an isolated feature of myocarditis? Eur J Pediatr 163: 410-411, 2004.

18. Kalpatthi R, Devas G, Pass R, Sharma J. Heart block in infant with atypical myocarditis: a case report and review of literature. Int J Cardiol 96: 113-115, 2004.

19. Duncan BW, Bohn DJ, Atz AM, French JW, Laussen PC, Wessel DL. Mechanical circulatory support for the treatment of children with acute fulminant myocarditis. J Thorac Cardiovasc Surg 122: 440-448, 2001.

20. Morimoto S, Kato S, Hiramitsu S, et al. Role of myocardial interstitial edema in conduction disturbances in acute myocarditis. Heart Vessels 21: 356-360, 2006.

21. Terasaki F, James TN, Nakayama Y, Deguchi H, Kitaura Y, Kawamura K. Ultrastructural alterations of the conduction system in mice exhibiting sinus arrest or heart block during Coxsackievirus B3 acute myocarditis. Am Heart J 123: 439-452, 1992.
22. Mahoney LT, Marvin WJ Jr, Atkins DL, Clark EB, Lauer RM. Pacemaker management for acute onset of heart block in childhood. J Pediatr 107: 207-211, 1985.

23. Prochnau D, Kühnert H, Heyne JP, Figulla HR, Surber R. Cardiac magnetic resonance imaging as a tool to link cardiac conduction disease to myocarditis with minimal left ventricular impairment. J Electrocardiol 45: 161-163, 2012.

24. Cooper LT, Baughman KL, Feldman AM, et al. American Heart Association; American College of Cardiology; European Society of Cardiology. The role of endomyocardial biopsy in the management of cardiovascular disease: a scientific statement from the American Heart Association, the American College of Cardiology, and the European Society of Cardiology. Circulation 116: 22162233, 2007.

25. JCS Joint Working Group. Guidelines for diagnosis and treatment of myocarditis (JCS 2009): digest version. Circ J 75: 734-743, 2011.

26. Klementowicz PT, Andrews C, Fisher JD, Feld M, Furman S. Lyme carditis: an important cause of reversible heart block. Ann Intern Med 110: 339-345, 1989.

(C) 2012 The Japanese Society of Internal Medicine http://www.naika.or.jp/imonline/index.html 